\title{
Assessing the Transport Potential of Polymeric Nanocapsules Developed for Crop Protection
}

ADAMO RICCARDO PETOSA, FARAZ RAJPUT, OLIVIA SELVAM,

CAROLIN ÖHL and NATHALIE TUFENKJI ${ }^{1^{*}}$

Department of Chemical Engineering, McGill University, 3610 University St., Montreal,

Quebec, Canada H3A OC5

${ }^{1}$ Corresponding Author:

Phone: (514) 398-2999; Fax: (514) 398-6678; E-mail: nathalie.tufenkji@mcgill.ca 


\section{Abstract}

Nanotechnology is increasingly important in the agricultural sector, with novel products being developed to heighten crop yields and increase pesticide efficacy. Herein, the transport potential of different polymeric nanocapsules ( $n$ CAPs) developed as pesticide delivery vehicles was assessed in model soil systems. The $n$ CAPs examined are (i) poly(acrylic acid)-based ( $n$ CAP1), (ii) poly(methacrylic acid)-ran-poly(ethyl acrylate) copolymer-based ( $n$ CAP2), (iii) poly(methacrylic acid-ran-styrene) copolymer-based ( $n$ CAP3), and (iv) poly(methacrylic acid-ran-butylmethacrylate)-based ( $n$ CAP4). $n$ CAP mobility was examined in columns packed with agricultural loamy sand saturated with artificial porewater containing $\mathrm{Ca}^{2+}$ and $\mathrm{Mg}^{2+}$ cations (10 mM ionic strength, $\mathrm{pH} 6$ and 8). Furthermore, the impact of (i) cation species, (ii) sand type, and (iii) ammonium polyphosphate fertilizer on the transport potential of a nanoformulation combining $n \mathrm{CAP} 4$ capsules and the pyrethroid bifenthrin ( $n$ CAP4-BIF) was examined and compared to a commercial bifenthrin formulation (Capture LFR). Although $n$ CAP4-BIF and Capture ${ }^{\circledast}$ LFR formulations were highly mobile in quartz sand saturated with $10 \mathrm{mM} \mathrm{NaNO}_{3}(\geq 95 \%$ elution), they were virtually immobile in the presence of $10 \%$ ammonium polyphosphate fertilizer. The presence of $\mathrm{Ca}^{2+}$ and $\mathrm{Mg}^{2+} \mathrm{did}$ not hinder $n$ CAP4-BIF elution in quartz sand saturated with $10 \mathrm{mM}$ standard CIPAC D synthetic porewater; however, limited Capture ${ }^{\circledast}$ LFR transport $(<10 \%$ elution) was observed under the same conditions. Capture ${ }^{\oplus}$ LFR also exhibited limited mobility in the presence or absence of fertilizer in loamy sand saturated with divalent salt solutions, whereas $n$ CAP4-BIF exhibited increased elution with time and enhanced transport upon the addition of fertilizer. Overall, $n$ CAP4 is a promising delivery vehicle in pyrethroid nanoformulations such as $n$ CAP4-BIF.

Keywords: bifenthrin, delivery, nanopesticide, polymeric capsule, pyrethroid, transport 


\section{INTRODUCTION}

Nanotechnology is increasingly applied in agriculture, with novel nanomaterials being developed and used in pesticide delivery, genetic plant transformation and the development of biopesticides and fertilizers (Ghormade et al. 2011). Polymer-based nanoformulations can improve pesticide efficiency by (i) decreasing the rate at which the active ingredient (AI) is released to the surrounding environment, (ii) protecting the AI against biodegradation and/or (iii) by increasing the transport potential of AIs with low water solubilities (Kah and Hofmann 2014). Loha et al. examined the performance of a nanoformulation consisting of poly(ethylene glycol)-based (PEG-based) nanospheres encapsulating the pyrethroid insecticide $\beta$-cyfluthrin against the cowpea seed beetle. The presence of the PEG-based nanospheres resulted in prolonged AI activity and decreased average half maximal effective concentrations $\left(\mathrm{EC}_{50}\right)$ versus a commercially available $\beta$-cyfluthrin formulation due to delayed insecticide release (Loha et al. 2012). In a recent study, Kah et al. found that nanoformulations had a significant impact on the fate of the pesticide bifenthrin, particularly in soil with low organic content. More specifically, the sorption and degradation of bifenthrin (as part of a nanoformulation) differed by up to a factor of 10 and 1.8 , respectively, when compared to the pure active compound (Kah et al. 2016).

Pyrethroid insecticides such as cyfluthrin and bifenthrin are manufactured analogues of pyrethrins, compounds with insecticidal properties found in flowers of the genus Chrysanthemum or Tanacetum. Effective against a broad array of insects and mites, pyrethroids are employed to treat crops, in nurseries and on construction sites (termite 
control). Pyrethroids are also the primary insecticides utilized in urbanized areas, having largely replaced organophosphate pesticides such as diazinon and chlorpyrifos (Frank and Marshall 2008, Weston et al. 2013). Consequently, American and European studies have identified various pyrethroids in municipal wastewater (Weston et al. 2013).

In the United States alone, the quantity of bifenthrin employed agriculturally has increased from an estimated 115,080 lbs between 1992 and 1995 to an estimated 844,000 lbs in 2009 (Pennington et al. 2014, Thelin and Gianessi 2000). These figures do not account for urban use, which has been reported to surpass agricultural application in some areas (Moran 2007). In a study investigating pesticide occurrence in urban wetland settings, bifenthrin exhibited the highest frequency of detection in wetland sediments, appearing in $33 \%$ of sites (Allinson et al. 2015).

The presence of bifenthrin in aquatic settings is worrisome as it has been found to be extremely toxic to fish and aquatic organisms. Among freshwater organisms, $96 \mathrm{~h} \mathrm{LC} 50$ values of $1.5 \times 10^{-4}, 3.5 \times 10^{-4}$ and $1.6 \times 10^{-3} \mathrm{ppm}$ bifenthrin have been reported for rainbow trout, bluegill sunfish and Daphnia magna, respectively (Fecko 1999). Among estuarine species, Harper et al. reported LC 50 values of $2.0 \times 10^{-5}, 1.3 \times 10^{-5}$ and $2.0 \times 10^{-2} \mathrm{ppm}$ for adult grass shrimp, larval grass shrimp and sheepshead minnow, respectively (Harper et al. 2008). Improved delivery of pyrethroids such as bifenthrin would potentially reduce the quantities required to effectively protect crops, therefore curbing unwanted impacts on non-target organisms. Conversely, within a nanoformulation, pyrethroid interactions with nanocarrier components may result in enhanced AI transport potential and persistence. Thus, adequate 
risk assessments must be performed to better predict the hazards posed to non-target organisms, along with the potential for groundwater and surface water contamination. Overall, the impact of the nanoformulation on AI transport, relocation and bioavailability should be examined closely (Fecko 1999).

Information regarding the mobility of nanocarriers (with and without associated AI) or the impact of nanoformulations on environmental fate processes remains limited.. Herein, the transport potential of polymeric nanocapsules ( $n \mathrm{CAPs}$ ) destined to facilitate the transport of various pesticides, including pyrethroids, was investigated prior to their inclusion in agricultural nanoformulations. While the $n$ CAPs examined have distinct compositions, they are all being developed in the aim of decreasing the need for costly and potentially harmful pesticides, thus mitigating their impact on the environment. Previous work examined the transport potential of a hollow $n$ CAP consisting of partially cross-linked poly(acrylic acid), PAA (Petosa et al. 2013). While these polymeric carriers were found to be highly mobile in quartz sand, the large number of carboxyl functional groups on the nanocapsule surface was found to favor interaction with clays present in loamy sand, thus decreasing nanocapsule transport (Petosa et al. 2013).

In developing polymeric nanocapsules for pesticide delivery, it is essential to consider (i) nanocapsule transport potential and (ii) nanocapsule-pesticide interactions. The former can be achieved using laboratory-scale soil- or sand-packed columns saturated with natural or artificial porewater. Herein, hollow $n$ CAP transport behavior in model saturated soil environments is investigated. Further studies are conducted with the aforementioned PAA 
$n$ CAPs (Petosa et al. 2013), and a series of experiments is performed with three other capsule types (described below), allowing for comparison. Additionally, the transport potential of a nanoformulation containing active bifenthrin and an $n$ CAP carrier consisting of poly(methacrylic acid-ran-butylmethacrylate) is considered and compared to that of the commercially available bifenthrin-containing formulation Capture LFR. Finally, the impact of a commonly used fertilizer on the mobility of the two bifenthrin-containing formulations is also considered. It is noteworthy that these conditions do not directly mimic the exact application scenario in an agricultural field (e.g., where soils may not be fully saturated with porewater and/or $n$ CAP application loads may not be as high as those used in this study). Nonetheless, the experiments described herein are essential in elucidating the fundamental interactions governing $n \mathrm{CAP}$-soil interactions.

\section{MATERIALS AND METHODS}

\subsection{SYNTHETIC POREWATER PROPERTIES}

Transport experiments were conducted using Collaborative International Pesticides Analytical Council (CIPAC) standard water D (i.e., CIPAC D), a synthetic porewater containing divalent salts $\left(2.74 \mathrm{mM} \mathrm{CaCl}_{2}\right.$ and $0.68 \mathrm{mM} \mathrm{MgCl} 2$ molar concentrations) and a total ionic strength (IS) of $10 \mathrm{mM}$. To verify the influence of the cation valence, selected transport experiments were also conducted using a monovalent salt solution of equivalent IS $\left(10 \mathrm{mM} \mathrm{NaNO}_{3}\right)$. Solution $\mathrm{pH}$ was adjusted with $\mathrm{NaOH}$. 


\subsection{GRANULAR COLLECTOR CHARACTERIZATION}

Columns were packed with loamy sand $\left(d_{50}=225 \mu \mathrm{m}\right)$ obtained at a $35 \mathrm{~cm}$ depth from an Agriculture and Agri-Food Canada (AAFC) farm plot located in St-Augustin-deDesmaures, Québec. Select experiments were conducted in quartz sand (-50+70 mesh size, $d_{50}=256 \mu \mathrm{m}$, Sigma-Aldrich) washed as described by Pelley and Tufenkji (Pelley and Tufenkji 2008). Details of loamy sand and quartz sand characterization have previously been published (Petosa et al. 2013, Quevedo and Tufenkji 2012).

\subsection{SUSPENSION PREPARATION}

Suspensions of hollow $n$ CAPs (Vive Crop Protection, Inc., Canada) were prepared using (i) $n$ CAP1, consisting of partially crosslinked PAA, (ii) $n$ CAP2, a 90:10 random copolymer with a hydrophilic poly(methacrylic acid) exterior and a relatively hydrophobic poly(ethyl acrylate) interior, (iii) $n$ CAP3, a 75:25 copolymer consisting of poly(methacrylic acid-ran-styrene), and (iv) nCAP4, a 75:25 copolymer consisting of poly(methacrylic acidran-butylmethacrylate). Note that "ran" indicates the capsules consist of random copolymers. The hollow $n$ CAP suspensions were prepared in CIPAC D (10 mM IS) at $\mathrm{pH} 6$ and $\mathrm{pH} 8$. A capsule concentration of $100 \mathrm{mg} / \mathrm{L}$ was employed in all experiments. Suspension $\mathrm{pH}$ was stabilized using $1 \mathrm{mM}$ MOPS and adjusted to $\mathrm{pH} 6$ or 8 using $\mathrm{NaOH}$.

Additional experiments were conducted with two distinct bifenthrin delivery systems. The first, a nanoformulation referred to herein as $n$ CAP4-BIF (Vive Crop Protection Inc., 
Canada), consists of the aforementioned $n \mathrm{CAP} 4$ polymeric capsules $(5-10 \mathrm{wt} \%)$, the pyrethroid insecticide bifenthrin $(20.3 \mathrm{wt} \%)$, as well as proprietary inert ingredients. Developed for in-furrow application, $n$ CAP4-BIF primarily targets soil insect pests. Tests were also conducted with the commercially available Capture LFR (i.e., liquid fertilizer

ready) soil insecticide bifenthrin formulation (FMC Corporation, USA). Capture LFR has a $17.15 \mathrm{wt} \%$ bifenthrin loading. The $\mathrm{pH}$ of the formulations as received is 5.3 ( $n$ CAP4-BIF) and 6.8 (Capture LFR). Suspensions of both formulations were prepared at $200 \mathrm{mg} / \mathrm{L} \mathrm{AI} \mathrm{(a}$ mid-range concentration targeted for real application) in $10 \mathrm{mM}$ CIPAC D or $10 \mathrm{mM}$ $\mathrm{NaNO}_{3}$ as model porewaters (at $\mathrm{pH}$ 6). Therefore, the AI (bifenthrin) to soil mass ratio used was $2.58 \times 10^{-4}$ (for application of 4 pore volumes, PVs, of $200 \mathrm{mg} / \mathrm{L}$ bifenthrin) and constant for both delivery systems. Capture LFR was developed for mixing with water or liquid fertilizer prior to application. Thus, $n$ CAP4-BIF and Capture LFR suspensions were also prepared in the presence of a 10\% v/v ammonium polyphosphate 10-34-0 fertilizer (Agrium Inc., Canada).

\subsection{NANOCAPSULE CHARACTERIZATION}

Nanocapsule electrophoretic mobilities (EPMs) were determined by laser Doppler velocimetry (ZetaSizer Nano ZS, Malvern). EPM measurements ( $\mathrm{n}=6$ for each suspension) were performed at $25^{\circ} \mathrm{C}$ for each experimental condition used in column experiments, with an applied electrical field of $4.9 \pm 0.1 \mathrm{~V} / \mathrm{m}$. EPM was also determined as a function of $\mathrm{pH}$ in an attempt to establish the $\mathrm{pH}$ of zero charge $\left(\mathrm{pH}_{\mathrm{zpc}}\right)$ for each type of nanocapsule. 
Nanocapsule hydrodynamic diameters were determined by dynamic light scattering (DLS) using a Malvern Zetasizer Nano ZS ( $\mathrm{n}=6$ for each suspension).

\subsection{NANOCAPSULE AND FORMULATION TRANSPORT STUDIES}

Transport studies in quartz and loamy sand-packed columns were performed as previously described (Petosa et al. 2013). The column packing and equilibration procedures described by Petosa et al. (Petosa et al. 2013) were used, resulting in $14 \mathrm{~cm}$ quartz sand and 7 cm loamy sand-packed column heights. Packed-bed porosities were 0.39 and 0.44 for quartz and loamy sand, respectively. A flow rate of $0.4 \mathrm{~mL} / \mathrm{min}$ (equivalent to a Darcy velocity of $2.86 \mathrm{~m} /$ day) was employed.

In total, 6.5 PVs of the hollow $n$ CAP suspensions $(100 \mathrm{mg} / \mathrm{L}$ in CIPAC D, $\mathrm{pH} 6$ or $\mathrm{pH}$ 8) was applied to loamy sand-packed columns. Influent $\left(C_{0}\right)$ and effluent $(C)$ particle concentrations were tracked online using a UV-visible spectrophotometer (Agilent 8453) equipped with a $1 \mathrm{~cm}$ flow-through cell. All eluting $n \mathrm{CAP}$ particle types were monitored at $210 \mathrm{~nm}$ where a distinctive absorbance peak was observed.

Furthermore, $n$ CAP4-BIF and Capture LFR formulation transport studies were conducted in $10 \mathrm{mM} \mathrm{NaNO}_{3}$ or CIPAC D (in the absence or presence of ammonium polyphosphate fertilizer) at $\mathrm{pH} 6$. Formulation transport was assessed in quartz and loamy sand-packed columns. When required, the fertilizer was added directly to the $\mathrm{NaNO}_{3}$ or CIPAC D, prior to $n$ CAP4-BIF or Capture LFR addition. Fertilizer was also included during column equilibration in these experiments. Unlike the hollow $n$ CAPs, the $n$ CAP4-BIF 
formulation was monitored at $700 \mathrm{~nm}$ where a distinctive absorbance peak was noted. For further confirmation, the elution of $n$ CAP4-BIF formulation from packed columns was also monitored using nanoparticle tracking analysis (NTA, Nanosight LM10, Wiltshire, UK). NTA was used to generate particle breakthrough curves using aliquots collected from select transport studies. Particle concentrations (particles $/ \mathrm{mL}$ ) were determined from NTA particle counts for the column influent $\left(C_{0}\right)$ and effluent $(C)$ aliquots. Each $4.8 \mathrm{~mL}$ aliquot analyzed by NTA represented the mean particle concentration eluting over 0.44 PVs (i.e., over 12 min). Since the $n$ CAP4-BIF formulation consisted of nanocapsules + nano-sized bifenthrin crystals, the NTA method effectively tracked the mobility of the formulation. Capture LFR elution was monitored using UV-visible spectrophotometry at $700 \mathrm{~nm}$. Finally, a nanoformulation containing all $n$ CAP4-BIF components, with the exception of bifenthrin (referred to hereafter as $n$ CAP4-UNLOADED) was also provided by Vive Crop Protection Inc. Select transport studies with $n$ CAP4-UNLOADED were conducted in quartz sand and loamy sand-packed columns. 


\section{RESULTS AND DISCUSSION}

Understanding the impact of a nanoformulation on processes including AI transport and bioavailability is essential in developing robust environmental risk assessments for nanopesticides (Kah and Hofmann 2014, Kookana et al. 2014). Herein, the mobility of four nanocarriers and that of a novel bifenthrin nanoformulation $(n \mathrm{CAP} 4-\mathrm{BIF})$ is investigated in sand and soil saturated with artificial porewater.

\subsection{Electrophoretic mobility of $n$ CAPs}

The effect of suspension $\mathrm{pH}$ on the EPM of $n$ CAPs suspended in $10 \mathrm{mM} \mathrm{NaNO}_{3}$ was examined (Figure S1). EPM was also determined for $n$ CAPs in CIPAC D at $\mathrm{pH} 6$ and 8 (Table 1 , influent samples). In CIPAC D at $\mathrm{pH} 6, n \mathrm{CAP} 3$ is the most charged nanocapsule, followed by $n$ CAP $1, n \mathrm{CAP} 2$, and $n$ CAP 4 . At $\mathrm{pH} 8$ in CIPAC D, $n$ CAP 1 exhibits the highest absolute EPM, followed by $n \mathrm{CAP} 2, n \mathrm{CAP} 3$, and $n \mathrm{CAP} 4$. Absolute EPM values range between 0.5 and $1.0 \mu \mathrm{mcmV}^{-1} \mathrm{~s}^{-1}$ for all the $n$ CAPs (Table 1).

\section{[TABLE_1_HERE]}

EPM measurements of $n$ CAP4-BIF and Capture LFR suspensions ( $\mathrm{pH}$ 6) show that the absolute EPM is significantly higher in monovalent $10 \mathrm{mM} \mathrm{NaNO}_{3}$ than in $10 \mathrm{mM}$ CIPAC D (Table 2). The decreased absolute EPM observed in CIPAC D results from increased electrical double-layer compression and a more effective screening of particle surface charge by the $\mathrm{Ca}^{2+}$ and $\mathrm{Mg}^{2+}$ divalent cations contained therein (Hunter 2001). Thus, while $n$ CAP4-BIF exhibits an EPM of $-6.0 \mu \mathrm{mcmV}^{-1} \mathrm{~s}^{-1}$ in $10 \mathrm{mM} \mathrm{NaNO}_{3}$, the EPM is -2.0 
$\mu \mathrm{mcmV}^{-1} \mathrm{~s}^{-1}$ in CIPAC D. Likewise, Capture ${ }^{\circledast} \mathrm{LFR}$ EPM is $-4.9 \mu \mathrm{mcmV}^{-1} \mathrm{~s}^{-1}$ in $\mathrm{NaNO}_{3}$, but 1.5 $\mathrm{m} \mathrm{m}^{-1} \mathrm{~cm}^{-1}$ in CIPAC D (Table 2). The addition of $10 \%$ fertilizer results in significantly decreased absolute EPMs for both formulations in $\mathrm{NaNO}_{3}$. Here, the ammonium $\left(\mathrm{NH}_{4}{ }^{+}\right)$ cations present in the ammonium polyphosphate fertilizer further screen particle surface charge, resulting in a decreased absolute EPM. In comparison, a much smaller change in EPM for both formulations was detected in CIPAC D (Table 2). This reflects the fact that surface charge screening is dominated by the divalent cations present in the CIPAC D. It is noteworthy that the EPM measurements should be interpreted with caution due to the variable polydispersity of the suspensions prepared in different solutions.

\section{[TABLE_2_HERE]}

\section{2. $n$ CAP SIZE}

In CIPAC D, $n$ CAP1 hydrodynamic diameter increases from $200 \pm 3$ to $258 \pm 7 \mathrm{~nm}$ as $\mathrm{pH}$ decreases from 8 to 6 (Table 1). The size of $n$ CAP2 in CIPAC D is $300 \pm 35 \mathrm{~nm}$ at $\mathrm{pH} 6$ and increases to $364 \pm 9 \mathrm{~nm}$ at $\mathrm{pH} 8$ (Table 1). These observations on the effect of $\mathrm{pH}$ on $n$ CAP1 and $n$ CAP2 particle size are in agreement with DLVO theory of colloidal stability; namely, increased aggregation is observed at lower absolute EPM where electrostatic particleparticle interactions are less repulsive (Derjaguin and Landau 1941, Verwey and Overbeek 1948). The average diameter of $n \mathrm{CAP} 4$ is unchanged from $\mathrm{pH} 6$ to 8 (Table 1). It can be noted that the magnitude of the absolute $n$ CAP4 EPMs observed at both $\mathrm{pH}$ is less than values observed for $n$ CAP1 and $n$ CAP2 under the same conditions (Table 1 ). Reproducible measurements of $n \mathrm{CAP} 3$ particle size could not be obtained at $\mathrm{pH} 6$, precluding a 
comparison with the other nanocapsules. Highly polydisperse $n \mathrm{CAP} 3$ influent samples (PdI $=1)$ at $\mathrm{pH} 6$ led to difficulties in obtaining reproducible measurements at these conditions. On the other hand, effluent samples were less polydisperse (Table 1), enabling reproducible DLS sizing data. Note that while high polydispersity index (PdI) values were also observed for $n$ CAP4 (Table 1), reproducible sizes were obtained. Still, the DLS size values are at best estimates as a broad range of particle sizes is likely present in suspension.

The $n$ CAP4-BIF and Capture LFR formulations have hydrodynamic diameters of $332 \pm 15$ and $710 \pm 67 \mathrm{~nm}$ in CIPAC D (determined by DLS, $200 \mathrm{ppm}$ bifenthrin) (Table 2). Overall, $n$ CAP4-BIF is significantly smaller than Capture LFR in this artificial porewater. Also, the $n$ CAP4-BIF formulation is less susceptible to aggregation in the presence of ammonium polyphosphate fertilizer. When compared to fertilizer-free suspensions, the addition of $10 \%$ ammonium polyphosphate fertilizer resulted in a $50 \%$ and $56 \%$ increase in $n$ CAP4-BIF size in $10 \mathrm{mM} \mathrm{NaNO}_{3}$ and CIPAC D, respectively. Upon the addition of $10 \%$ fertilizer to Capture LFR suspensions, size increased by $380 \%$ in $10 \mathrm{mM} \mathrm{NaNO}_{3}$ and $165 \%$ in CIPAC D (Table 2). It is important to note that particle sizes determined by DLS are strongly biased by the largest aggregates present in a polydisperse suspension (Domingos et al. 2009). The $n$ CAP4-BIF suspensions had PdI values of 0.34 and 0.31 in fertilizer-free 10 $\mathrm{mM} \mathrm{NaNO}_{3}$ and CIPAC D, respectively (Table 2). Likewise, the Capture LFR suspensions exhibited PdI values of 0.25 and 0.39 in fertilizer-free $10 \mathrm{mM} \mathrm{NaNO}_{3}$ and CIPAC D, respectively. Thus, while DLS sizes reported herein are useful for observing general trends with changing water chemistry, the absolute values should be interpreted with caution due to 
inherent polydispersity of the suspensions. It should also be noted that the addition of fertilizer resulted in decreased polydispersity (Table 2). This is likely due to the fact that fewer smaller aggregates remain in the presence of fertilizer, resulting in more uniformly sized larger aggregates.

\subsection{NANOCAPSULE TRANSPORT IN SOIL AND SAND}

\subsection{1. nCAP1 transport behavior}

The $n$ CAP1 particles exhibit distinct transport behaviors at $\mathrm{pH} 6$ and 8 . When suspended in CIPAC D, virtually all particles are retained in the $7 \mathrm{~cm}$ loamy sand-packed columns at $\mathrm{pH} 6$ (Figure 1a), while approximately 30\% $n$ CAP1 elution is observed at $\mathrm{pH} 8$ (at 4 PVs). Nanocapsule EPM remains essentially unchanged for $n$ CAP1 at $\mathrm{pH} 6$ and 8; thus, differences in electrostatic particle-surface interactions cannot explain the different nanocapsule deposition behaviors. Influent and effluent nanocapsule aggregate sizes (Table 1) suggest that the difference in $n \mathrm{CAP} 1$ transport potential can partly be attributed to physical straining of larger aggregates at pH 6 (Petosa et al. 2012, Petosa et al. 2010, Raychoudhury et al. 2014).

Physical straining is characterized by the entrapment of larger particle aggregates in the pores between collector (i.e., sand) grains. As the pores become clogged, incoming particles will become entrapped, further limiting elution (Basnet et al. 2013, Bradford et al. 2002, Petosa et al. 2013, Quevedo et al. 2014). While $n$ CAP1 has an average influent hydrodynamic diameter of $200 \pm 3 \mathrm{~nm}$ at $\mathrm{pH} 8$, the particle size in the influent is $258 \pm 7 \mathrm{~nm}$ at 
pH 6 (Table 1). Furthermore, while dry sieve analysis indicates that the loamy sand grains employed in this study had a mean diameter of $225 \mu \mathrm{m}$, the grains were also found to exhibit a broad size distribution (Quevedo and Tufenkji 2012). Approximately 20\% of the grains are between $105-150 \mu \mathrm{m}$ in size. It is likely that the finer loamy sand grains result in straining of the larger $n$ CAP1 aggregates present at $\mathrm{pH} 6$. Finally, in comparing the $n \mathrm{CAP} 1$ influent and effluent sizes presented in Table 1, it is apparent that effluent size $(118 \mathrm{~nm})$ is significantly smaller than influent size $(258 \mathrm{~nm})$ at $\mathrm{pH} 6$. However, this is not as significant at $\mathrm{pH} 8$, where size in the influent $(200 \mathrm{~nm})$ and effluent $(191 \mathrm{~nm})$ remains nearly unchanged. All aforementioned observations support the theory that a greater number of larger aggregates are entrapped within the packed bed at $\mathrm{pH}$ 6. In a real-world agricultural application scenario, straining may be less significant due to lower nanoformulation loadings. Besides physical straining, the enhanced transport observed at $\mathrm{pH} 8$ may also in part be due to the presence of clays such as allophane in the loamy sand (Petosa et al. 2013, Quevedo and Tufenkji 2012, Sposito 1989). The $\mathrm{pH}_{\text {zpc }}$ for allophane with an Al/Si molar ratio of 1.26 is reported to be $\mathrm{pH} 6.7$ ( $\mathrm{Su}$ and Harsh 1993). Thus, allophanes present in the loamy sand provide favorable deposition sites for the negatively charged $n$ CAPs at $\mathrm{pH} 6$, leading to decreased nanocapsule transport potential. At the higher $\mathrm{pH}$ of 8 (above the allophane $\mathrm{pH}_{\mathrm{zpc}}$, fewer positively charged sites will be available, resulting in the enhanced transport observed.

The dynamic elution behavior observed at $\mathrm{pH} 8$ (i.e., increasing $n \mathrm{CAP} 1$ elution with time) (Figure 1a) is suggestive of blocking effects within the granular matrix (Liu et al. 1995, 
Petosa et al. 2013). The loamy sand packing may present a finite number of favorable deposition sites due to grain surface roughness, chemical heterogeneities and the presence of clays. Once occupied, the depletion of these favorable sites results in heightened particle elution. Given the polymeric composition of the $n$ CAPs, electrosteric repulsion may also play an important role in preventing deposition onto favorable sites adjacent to deposited $n$ CAPs (Ko and Elimelech 2000, Petosa et al. 2013), further enhancing particle elution.

To ensure that the increase in absorbance with time observed is not due to the release of light absorbing materials from the loamy sand, nanocapsule-free CIPAC D was introduced to fresh columns for several PVs and the effluent absorbance was recorded. A negligible increase in absorbance over time was observed in the absence of nanocapsules. Although negligible, the measured background absorbance was subtracted from all effluent absorbance values obtained from columns injected with nanocapsule suspensions. Note that all packed columns were used only once.

\section{[FIGURE_1_HERE]}

\subsection{2. $n$ CAP2 transport behavior}

The elution of $n$ CAP2 is considerably delayed, with limited transport initially observed in the loamy sand at pH 6 and 8 (Figure 1b and S2b). Nanocapsule breakthrough only becomes apparent beyond 4 PVs (Fig. S2b shows transport behavior for longer injection times). At 6 PVs of $n$ CAP2 injection, we observe 14 and $32 \%$ elution at $\mathrm{pH} 6$ and 8 , respectively. Slightly greater $n \mathrm{CAP} 2$ elution is observed at $\mathrm{pH} 8$ (Figure $1 \mathrm{~b}$ and S2b), yet nanocapsule EPM is comparable at the two $\mathrm{pHs}\left(-0.7 \mu \mathrm{mcmV}^{-1} \mathrm{~s}^{-1}\right.$ at $\mathrm{pH} 8$ versus -0.8 
$\mu \mathrm{mcmV}^{-1} \mathrm{~s}^{-1}$ at $\mathrm{pH}$ 6). As described for $n \mathrm{CAP} 1$, allophane may be responsible for the differences. While allophanes provide favorable deposition sites for the negatively charged $n \mathrm{CAP} 2$ capsules at $\mathrm{pH} 6$, at $\mathrm{pH} 8$ (above the allophane $\mathrm{pH}_{\text {zpc }}$ ), fewer positively charged sites will be available, enhancing $n \mathrm{CAP} 2$ transport potential. The dynamic elution behavior exhibited by $n \mathrm{CAP} 2$ can be attributed to increased nanocapsule elution as favorable deposition sites on grain surfaces become occupied (i.e., blocking effect). Furthermore, effluent nanocapsule sizes are significantly smaller than influent sizes at both $\mathrm{pHs}$, suggesting that physical straining is occurring at both $\mathrm{pH} 6$ and 8 , further contributing to the observed dynamic elution behavior.

\subsection{3. $n C A P 3$ and $n C A P 4$ transport behavior}

Although $n \mathrm{CAP} 3$ and $n \mathrm{CAP} 4$ have a negative surface charge at $\mathrm{pH} 6$ and 8 (Table 1), limited mobility is observed in the loamy sand-packed columns, likely due to interaction with organic components in the sand (Figure 2). No delayed nanocapsule breakthrough is observed even after the application of 6 PVs of nanocapsule suspension (Figure S2). Less than $10 \%$ of the applied $n \mathrm{CAP} 3$ is observed to elute from the loamy sand and nanocapsule elution remains steady with extended application times (Figure S2c). In contrast, $n$ CAP4 is slightly more mobile, with approximately 20 and $12 \%$ elution observed at $\mathrm{pH} 6$ and 8 , respectively (Figure S2d).

Given that (i) $n \mathrm{CAP} 3$ and $n \mathrm{CAP} 4$ effluent particle sizes are larger than influent sizes (Table 1 ), and that (ii) measured $n \mathrm{CAP} 3$ and $n \mathrm{CAP} 4$ influent aggregate sizes $(\mathrm{pH} 8)$ are 
smaller than those observed for $n \mathrm{CAP} 1$ and $n \mathrm{CAP} 2$ (Table 1), factors other than physical straining are likely involved in the retention of these nanocapsules. Overall, each polymer used in the fabrication of the different nanocapsules will have different affinity to the various components of the heterogeneous loamy sand. Likewise, the polymers will respond differently to changes in salt concentration and $\mathrm{pH}$. These differences influence nanocapsule transport and complicate direct comparisons between the different $n$ CAPs examined.

To better understand the impact of polymer composition on the differences in $n$ CAP transport potential, the monomers present in the nanocapsules were considered. Examination of the monomeric composition of the $n$ CAPs reveals that $n$ CAP2 contains $90 \%$ methacrylic acid, while $n \mathrm{CAP} 3$ and $n \mathrm{CAP} 4$ contain $75 \%$ methacrylic acid. Methacrylic acid has a water solubility of $89 \mathrm{~g} / \mathrm{L}$ at $20^{\circ} \mathrm{C}$ (Riddick et al. 1985). The monomers making up the remainder of the nanocapsules all feature distinct solubilities. The ethyl acrylate present in $n \mathrm{CAP} 2$ is the most soluble in water $\left(15 \mathrm{~g} / \mathrm{L}\right.$ at $\left.25^{\circ} \mathrm{C}\right)$, followed by the butyl methacrylate $(0.8$ $\mathrm{g} / \mathrm{L}$ at $25^{\circ} \mathrm{C}$ ) in $n \mathrm{CAP} 4$ and the styrene $\left(0.3 \mathrm{~g} / \mathrm{L}\right.$ at $\left.25^{\circ} \mathrm{C}\right)$ in $n \mathrm{CAP} 3$ (Penzel 2008, Riddick et al. 1985, Yalkowsky et al. 2010). Given that the transport potential for $n$ CAP2 $>n$ CAP4 $>$ $n \mathrm{CAP} 3$, mobility of the methacrylic acid-containing $n$ CAPs in the packed columns appears to be directly correlated with monomer solubility. Likewise, since $n$ CAP1 is composed solely of PAA, a greater number of monomer carboxyl groups will be deprotonated at $\mathrm{pH} 8$ resulting in capsules bearing a greater negative charge. This enhanced negative charge in part renders $n \mathrm{CAP} 1$ more mobile at $\mathrm{pH} 8$, as deposition onto the negatively charged sand grains is less favorable. 
[FIGURE_2_HERE]

\subsection{4. $n$ CAP4-BIF and Capture LFR transport behavior}

The development of insecticidal nanoformulations has in part been driven by the limited water solubility of several insecticide AI and the need for effective delivery systems when applying the AI to the field (Kah and Hofmann 2014). Pyrethroids such as bifenthrin are hydrophobic compounds, exhibiting low water solubility and high octanol/water partitioning coefficients $\left(K_{\mathrm{OW}}\right)$ (Koskinen et al. 2006). The water solubility of bifenthrin is $0.1 \mathrm{mgL}^{-1}$ at $25^{\circ} \mathrm{C}$ (Fecko 1999). In the absence of a carrier, pyrethroids are expected to exhibit limited transport in water saturated soils. Kaufman et al. examined the transport of the pyrethroid decamethrin in soil-packed columns. The pesticide was found to be immobile in loamy clay and loamy sand. However, certain pyrethroid degradation products exhibited enhanced mobility (Kaufman et al. 1981). Pesticide transport potential is largely affected by sorption (Kah and Hofmann 2014). Factors affecting pesticide sorption to soils include soil type, the presence of organic matter, AI carrier characteristics (if applicable), $\mathrm{pH}$ and temperature (Silva et al. 2011).

The $n$ CAPs investigated herein were developed to enhance pesticide delivery. The mobility of $n$ CAP4-BIF, a nanoformulation containing $n$ CAP4 and active bifenthrin, was examined in columns packed with quartz or loamy sand. According to the manufacturer, the $n$ CAP4 polymeric capsule was selected as a promising delivery vehicle as it was hypothesized that the hydrophobic nature of bifenthrin would result in improved AI- $n$ CAP interactions with the more hydrophobic portions of the carrier. The elution of $n$ CAP4-BIF from the sand 
packed columns was monitored using UV-visible spectrophotometry at $700 \mathrm{~nm}$ and was compared to that of a commercial formulation, Capture LFR. Capture LFR was selected as it is readily available and possesses a bifenthrin loading similar to that of $n$ CAP4-BIF (17.2 wt $\%$ versus $20.3 \mathrm{wt} \%$ for $n$ CAP4-BIF). If applied at planting, pesticide formulations such as Capture $^{\circ}$ LFR can be delivered into the soil (e.g., to protect against rootworm larvae, wireworms or army cutworms) using either open furrow T-band application or in-furrow application.

Transport experiments conducted using quartz sand-packed columns saturated with $10 \mathrm{mM} \mathrm{NaNO}_{3}\left(\mathrm{pH}\right.$ 6) demonstrate that $n$ CAP4-BIF and Capture ${ }^{\circ}$ LFR are highly mobile (Figure 3a), with > 98\% and > 95\% elution, respectively. However, in the presence of $10 \%$ ammonium polyphosphate fertilizer, no elution is observed with either formulation. This is likely due to the significant decrease in absolute EPM and increased aggregate sizes observed for both formulations in the presence of the ammonium polyphosphate fertilizer (Table 2, in $10 \mathrm{mM} \mathrm{NaNO}_{3}$ ). As the formulations and quartz sand grains have a negative surface charge, decreased $n$ CAP4-BIF and Capture ${ }^{\circ}$ LFR absolute EPMs in the presence of fertilizer can result in more favorable retention conditions as particle-grain surface electrostatic interactions will be less repulsive. Moreover, the larger sizes of nanocapsule aggregates can result in physical straining within the packed bed (Bradford et al. 2002, Elimelech and O'Melia 1990, Petosa et al. 2012, Petosa et al. 2010).

In the absence of fertilizer, $n$ CAP4-BIF remains highly mobile in quartz sand-packed columns saturated with CIPAC D (Figure 3b). Under such conditions, the nanoformulation 
exhibits approximately $99 \%$ elution following application of 4 PVs of the suspension. In contrast, no more than $9 \%$ of the Capture LFR is found to elute under the same conditions. Given the large $710 \pm 67 \mathrm{~nm}$ aggregate size observed in CIPAC D (Table 2), the limited Capture $^{\oplus}$ LFR transport potential is likely due to physical straining in the granular matrix. In the presence of fertilizer, essentially no elution is observed with both formulations in the quartz sand (Figure 3b). While no major change in particle EPM is observed following addition of fertilizer to CIPAC D, formulation size increases significantly, reaching $519 \pm 16$ $\mathrm{nm}$ for $n$ CAP4-BIF and $1880 \pm 109 \mathrm{~nm}$ for Capture LFR. Thus, physical straining of the formulations is highly likely under these conditions.

[FIGURE_3_HERE]

In loamy sand-packed columns saturated with CIPAC D ( $\mathrm{pH}$ 6), virtually all of the Capture ${ }^{\bullet}$ LFR is retained, regardless of the presence or absence of fertilizer (Figure 3c). Factors contributing to the limited mobility of the formulation include (i) decreased absolute EPM in the presence of divalent cations, (ii) large aggregate sizes $(710 \pm 67$ and $1880 \pm 109 \mathrm{~nm}$ in the absence and presence of fertilizer, respectively), and (iii) sand grain surface charge heterogeneities and the presence of clays such as allophanes providing favorable deposition sites. Interestingly, in the absence of fertilizer, $n$ CAP4-BIF exhibits increased elution with time, exceeding 13\% elution at $4.5 \mathrm{PVs}$ (Figure 3c). The shape of the nanoformulation breakthrough curve indicates that elution would likely continue to increase beyond this level with longer injection. This suggests the occurrence of a limited number of favorable deposition sites resulting from the presence of surface charge heterogeneities and clays within 
the loamy sand. Physical straining likely plays a more limited role for $n$ CAP4-BIF as the aggregates of this nanoformulation are significantly smaller than those observed for Capture ${ }^{\circ}$ LFR (Table 2). Interestingly, in the presence of fertilizer, approximately $25 \% n$ CAP4-BIF elution is observed, nearly twice that which is observed without fertilizer (Figure 3c). This result is surprising given that no $n$ CAP4-BIF elution was detected in the effluent of quartz sand-packed columns when fertilizer was present. These observations suggest that interactions between components of the loamy sand (namely the allophane) and the fertilizer render the latter less inhibitory to nanoformulation transport. The adsorption of phosphate and polyphosphates to allophane has previously been demonstrated (Imai et al. 1981, Theng et al. 1982, Yoshinaga and Yamaguchi 1970). In the absence of the ammonium polyphosphate fertilizer, the allophane present in the loamy sand may offer favorable $n$ CAP4BIF deposition sites at $\mathrm{pH} 6$. However, these sites may not be available to $n$ CAP4-BIF once the soil is pre-equilibrated with fertilizer. Ammonium polyphosphate fertilizer consists of negatively charged polymer chains composed of phosphoric acid derived monomers and monovalent ammonium $\left(\mathrm{NH}_{4}^{+}\right)$cations. When ammonium polyphosphate fertilizer is added to loamy sand at $\mathrm{pH} 6$, the negatively charged polymers may adhere to the positively charged allophane, thus precluding subsequent $n$ CAP4-BIF deposition onto the clays. This ultimately results in the heightened $n$ CAP4-BIF elution observed. Increased Capture LFR elution from loamy sand-packed columns pre-equilibrated with fertilizer is not observed. Here, straining of the significantly larger Capture LFR aggregates (Table 2) likely dominates transport behavior. 
Finally, the impact of bifenthrin on the mobility of the $n$ CAP4 delivery vehicle was investigated by comparing $n$ CAP4-BIF transport potential to that of $n$ CAP4-UNLOADED (Figure 4). In quartz sand-packed columns saturated with CIPAC D, the presence of bifenthrin has no impact on nanocapsule transport, with $\sim 98 \%$ elution of $n$ CAP4UNLOADED and $n$ CAP4-BIF observed (Figure 4a). Under such conditions, $n$ CAP4UNLOADED was found to be small, with a hydrodynamic diameter of $169 \pm 0.1 \mathrm{~nm}$ (compared to $332 \pm 15$ for $n$ CAP4-BIF).

\section{[FIGURE_4_HERE]}

In loamy sand saturated with CIPAC D, the presence of bifenthrin has a more significant impact on nanoformulation transport. Whereas $>55 \%$ elution is observed for $n$ CAP4-UNLOADED, only $-14 \%$ of the $n$ CAP4-BIF elutes (Figure $4 \mathrm{~b}$ ). Enhanced $n$ CAP4BIF retention in CIPAC D may be due to the hydrophobic nature of pyrethroids, such as the bifenthrin in $n$ CAP4-BIF, which causes them to adhere to soil particles (Fecko 1999, Oudou and Hansen 2002). Thus, any exposed bifenthrin present in the $n$ CAP4-BIF formulation may also enhance nanocapsule deposition. Given that bifenthrin carries no charge, it can bind to sites of grain surfaces that would repel the negatively-charged nanocapsules. Bound bifenthrin can enhance nanocapsule deposition either directly (bifenthrin associated with $n \mathrm{CAP} 4$ binds to the grain surface) or indirectly (free bifenthrin adsorbs to the grain surface, thereby rendering nanocapsule deposition more favorable). In the absence of bifenthrin, negatively charged nanocapsules are limited to favorable deposition sites such as clays. As the 
favorable sites are occupied, overall elution increases at a greater rate than is observed for $n$ CAP4-BIF (Figure 4b).

To confirm that the $n$ CAP4-BIF formulation was effectively being tracked in column influent and effluent suspensions, particle breakthrough curves were generated using NTA and compared to UV-Visible absorbance measurements (Supplementary Materials, Figure S3). Overall, the breakthrough curves obtained using the two techniques are very similar, suggesting that they are both detecting the same formulation components.

NTA is a light scattering technique used in determining suspended nanomaterial size and size distributions. Under optimal conditions, it can track particles ranging from 10 to $1000 \mathrm{~nm}$ in diameter (Carr et al. 2008). Given the NTA's detection capabilities and the fact that UV-Visible and NTA-based breakthrough curves are very similar (Figure S3), it can be concluded that nanosized $n$ CAP4-BIF components are being detected and are responsible for the curves generated.

While these results confirm that nanosized $n$ CAP4-BIF components can be monitored to examine transport potential, release of the AI from the polymeric capsules was not investigated in this study. Nonetheless, elucidation of AI release in model soil systems is of great interest and essential in confirming that $n \mathrm{CAP} 4$ is an effective delivery vehicle for pyrethroid nanoformulations. AI release will be the focus of future studies.

It is worth noting that while efforts were made to best model agricultural application conditions, the bench-scale column experiments used in this study do present operational differences. For instance, in field application, soil would not necessarily be pre-equilibrated 
with fertilizer or fully saturated. Also, AI to soil ratios may be different in real-world scenarios. Nonetheless, this study provides essential insights into (i) the interactions between novel $n \mathrm{CAP}$ delivery systems and model agricultural soil and (ii) the mechanisms governing $n \mathrm{CAP}$ mobility.

\section{CONCLUSIONS}

In this study, four types of polymeric nanocapsules were found to exhibit varying transport potentials in water saturated agricultural loamy sand. Overall, the poly(methacrylic acid)-ran-poly(ethyl acrylate) copolymer-based $n$ CAP2 demonstrated the greatest transport potential, with 14 and 32\% elution at $\mathrm{pH} 6$ and 8 (at $6 \mathrm{PVs}$ ), respectively. While the poly(acrylic acid)-based $n$ CAP1 also exhibited significant mobility at $\mathrm{pH} 8$, it was virtually immobile at $\mathrm{pH} 6$ due to enhanced aggregation and physical straining. Both aforementioned capsule types display delayed particle breakthrough from loamy sand-packed columns, likely due to the presence of a finite number of favorable deposition sites resulting from chemical heterogeneities and clays such as allophane. While the poly(methacrylic acid-ranbutylmethacrylate)-based $n$ CAP 4 exhibited some mobility at $\mathrm{pH} 6$ (20\% elution), poly(methacrylic acid-ran-styrene) copolymer-based $n \mathrm{CAP} 3$ elution did not exceed $10 \%$.

The transport potential of two bifenthrin delivery systems was also evaluated in this study; both were highly mobile in quartz sand saturated with $\mathrm{NaNO}_{3}$ solution (10 mM IS, $\mathrm{pH}$ 6). In CIPAC D artificial porewater containing $\mathrm{Ca}^{2+}$ and $\mathrm{Mg}^{2+}$ (10 mM IS, $\mathrm{pH}$ 6), virtually all $n$ CAP4-BIF eluted from quartz sand; however, $<10 \%$ Capture $^{\bullet}$ LFR elution was 
observed under this condition. Finally, the addition of $10 \%$ ammonium polyphosphate fertilizer rendered both formulations immobile in quartz sand saturated with monovalent or divalent salt solutions. In loamy sand saturated with CIPAC D, Capture ${ }^{\circ}$ LFR was immobile in the presence and absence of fertilizer. Conversely, $n$ CAP4-BIF exhibited increasing elution with time (achieving 13\% elution at 4.5 PVs) in CIPAC D. Furthermore, enhanced $n$ CAP4BIF transport (25\% elution) was observed upon the addition of fertilizer. Overall, this study provides new insights into the interactions between $n$ CAP delivery systems and model agricultural soil and the mechanisms governing $n \mathrm{CAP}$ transport potential. Furthermore, $n$ CAP4 appears to be a promising pyrethroid delivery vehicle for inclusion in pesticide nanoformulations such as $n$ CAP4-BIF. 


\section{ACKNOWLEDGEMENTS}

This research was supported by NSERC, the Ministère du développement économique, innovation et exportation du Québec, the CRC Program, Environment Canada, Vive Crop Protection Inc., and the CFI. ARP was partially funded by NSERC (PGS) and a McGill Engineering Doctoral

Award. FR and OS were partially supported by a McGill SURE award. The authors also thank K. J. Wilkinson (U. Montreal) for NTA assistance and D. Anderson, D. Norton, R. Fraser, M.

Coulter, J. Dinglasan, and P. Thomson (Vive Crop Protection Inc.) for helpful discussions. 


\section{REFERENCES}

Allinson, G., Zhang, P., Bui, A., Allinson, M., Rose, G., Marshall, S. and Pettigrove, V. (2015) Pesticide and trace metal occurrence and aquatic benchmark exceedances in surface waters and sediments of urban wetlands and retention ponds in Melbourne, Australia. Environ Sci Pollut Res Int 22(13), 10214-10226.

Basnet, M., Ghoshal, S. and Tufenkji, N. (2013) Rhamnolipid biosurfactant and soy protein act as effective stabilizers in the aggregation and transport of palladium-doped zerovalent iron nanoparticles in saturated porous media. Environ Sci Technol 47(23), 13355-13364.

Bradford, S.A., Yates, S.R., Bettahar, M. and Simunek, J. (2002) Physical factors affecting the transport and fate of colloids in saturated porous media. Water Resources Research 38(12), 631-6312.

Carr, B., Malloy, A. and Warren, J. (2008) Nanoparticle tracking analysis. Innovations in Pharmaceutical Technology (26), 38-40.

Derjaguin, B.V. and Landau, L.D. (1941) Theory of stability of strongly charged lyophobic sols and the adhesion of strongly charged particles in solutions of electrolytes. Acta Physicochimica URSS 14, 633-662.

Domingos, R.F., Baalousha, M.A., Ju-Nam, Y., Reid, M.M., Tufenkji, N., Lead, J.R., Leppard, G.G. and Wilkinson, K.J. (2009) Characterizing manufactured nanoparticles in the environment: Multimethod determination of particle sizes. Environmental Science \& Technology 43(19), 7277-7284.

Elimelech, M. and O'Melia, C.R. (1990) Kinetics of deposition of colloidal particles in porous media. Environmental Science and Technology 24(10), 1528-1536.

Fecko, A. (1999) Environmental fate of bifenthrin, Department of Pesticide Regulation, Sacramento, CA.

Frank, S. and Marshall, L. (2008) Synthetic Pyrethroids, pp. 3-25, American Chemical Society.

Ghormade, V., Deshpande, M.V. and Paknikar, K.M. (2011) Perspectives for nano-biotechnology enabled protection and nutrition of plants. Biotechnology Advances 29(6), 792-803.

Harper, H.E., Pennington, P.L., Hoguet, J. and Fulton, M.H. (2008) Lethal and sublethal effects of the pyrethroid, bifenthrin, on grass shrimp (Palaemonetes pugio) and sheepshead minnow (Cyprinodon variegatus). Journal of Environmental Science and Health, Part B 43(6), 476-483.

Hunter, R.J. (2001) Foundations of Colloid Science, Oxford University Press Inc., New York.

Imai, H., Goulding, K.W.T. and Talibudeen, O. (1981) Phosphate adsorption in allophanic soils. Journal of Soil Science 32(4), 555-570.

Kah, M., Weniger, A.K. and Hofmann, T. (2016) Impacts of (Nano)formulations on the Fate of an Insecticide in Soil and Consequences for Environmental Exposure Assessment. Environ Sci Technol.

Kah, M. and Hofmann, T. (2014) Nanopesticide research: current trends and future priorities. Environment International 63, 224-235. 
Kaufman, D.D., Russell, B.A., Helling, C.S. and Kayser, A.J. (1981) Movement of cypermethrin, decamethrin, permethrin, and their degradation products in soil. Journal of Agricultural and Food Chemistry 29(2), 239-245.

Ko, C.H. and Elimelech, M. (2000) The 'shadow effect' in colloid transport and deposition dynamics in granular porous media: Measurements and mechanisms. Environmental Science and Technology 34(17), 36813689.

Kookana, R.S., Boxall, A.B., Reeves, P.T., Ashauer, R., Beulke, S., Chaudhry, Q., Cornelis, G., Fernandes, T.F., Gan, J., Kah, M., Lynch, I., Ranville, J., Sinclair, C., Spurgeon, D., Tiede, K. and Van den Brink, P.J. (2014) Nanopesticides: guiding principles for regulatory evaluation of environmental risks. J Agric Food Chem 62(19), $4227-4240$.

Koskinen, W.C., Rice, P.J. and Seebinger, J. (2006) Experimental variability in characterization of cyfluthrin sorption to soil. Journal of Environmental Science and Health, Part B 41(4), 323-331.

Liu, D., Johnson, P.R. and Elimelech, M. (1995) Colloid deposition dynamics in flow through porous media: Role of electrolyte concentration. Environmental Science and Technology 29(12), 2963-2973.

Loha, K.M., Shakil, N.A., Kumar, J., Singh, M.K. and Srivastava, C. (2012) Bio-efficacy evaluation of nanoformulations of beta-cyfluthrin against Callosobruchus maculatus (Coleoptera: Bruchidae). Journal of Environmental Science and Health, Part B 47(7), 687-691.

Moran, K.D. (2007) Pesticides in urban surface water: Urban pesticides use trends annual report 2007 TDC Environmental, LLC, San Mateo, CA.

Oudou, H.C. and Hansen, H.C. (2002) Sorption of lambda-cyhalothrin, cypermethrin, deltamethrin and fenvalerate to quartz, corundum, kaolinite and montmorillonite. Chemosphere 49(10), 1285-1294.

Pelley, A.J. and Tufenkji, N. (2008) Effect of particle size and natural organic matter on the migration of nanoand microscale latex particles in saturated porous media Journal of Colloid and Interface Science 321(1), 74-83.

Pennington, P.L., Harper-Laux, H., Sapozhnikova, Y. and Fulton, M.H. (2014) Environmental effects and fate of the insecticide bifenthrin in a salt-marsh mesocosm. Chemosphere 112, 18-25.

Penzel, E. (2008) Ullman's Encyclopedia of Industrial Chemistry, $7^{\text {th }}$ Edition, John Wiley and Sons, New York, NY.

Petosa, A.R., Öhl, C., Rajput, F. and Tufenkji, N. (2013) Mobility of nanosized cerium dioxide and polymeric capsules in quartz and loamy sands saturated with model and natural groundwaters. Water Res 47(15), 58895900.

Petosa, A.R., Brennan, S.J., Rajput, F. and Tufenkji, N. (2012) Transport of two metal oxide nanoparticles in saturated granular porous media: Role of water chemistry and particle coating. Water Research 46(4), 12731285.

Petosa, A.R., Jaisi, D.P., Quevedo, I.R., Elimelech, M. and Tufenkji, N. (2010) Aggregation and deposition of engineered nanomaterials in aquatic environments: Role of physicochemical interactions. Environmental Science and Technology 44(17), 6532-6549. 
Quevedo, I.R., Olsson, A.L.J., Clark, R.J., Veinot, J.G.C. and Tufenkji, N. (2014) Interpreting Deposition Behavior of Polydisperse Surface-Modified Nanoparticles Using QCM-D and Sand-Packed Columns. Environmental Engineering Science 31(7), 326-337.

Quevedo, I.R. and Tufenkji, N. (2012) Mobility of functionalized quantum dots and a model polystyrene nanoparticle in saturated quartz sand and loamy sand. Environmental Science and Technology 46(8), 44494457.

Raychoudhury, T., Tufenkji, N. and Ghoshal, S. (2014) Straining of polyelectrolyte-stabilized nanoscale zero valent iron particles during transport through granular porous media. Water Res 50, 80-89.

Riddick, J.A., Bunger, W.B. and Sakano, T.K. (1985) Techniques of Chemistry $4^{\text {th }}$ Edition, John Wiley and Sons, New York, NY.

Shen, C., Huang, Y., Li, B. and Jin, Y. (2008) Effects of solution chemistry on straining of colloids in porous media under unfavorable conditions. Water Resources Research 44(W05419), 1-12.

Silva, M.d.S., Cocenza, D.S., Grillo, R., Melo, N.F.S.d., Tonello, P.S., Oliveira, L.C.d., Cassimiro, D.L., Rosa, A.H. and Fraceto, L.F. (2011) Paraquat-loaded alginate/chitosan nanoparticles: Preparation, characterization and soil sorption studies. Journal of Hazardous Materials 190(1-3), 366-374.

Sposito, G. (1989) The Chemistry of Soils, Oxford University Press, Inc., New York.

Su, C. and Harsh, J.B. (1993) The electrophoretic mobility of imogolite and allophane in the presence of inorganic anions and citrate. Clays and Clay Minerals 41(4), 461-471.

Thelin, G.P. and Gianessi, L.P. (2000) Method for estimating pesticide use for county areas of the conterminous United States, US Geological Survey, US Department of the Interior, Sacramento, CA.

Theng, B.K.G., Russell, M., Churchman, G.J. and Parfitt, R.L. (1982) Surface properties of allophane, halloysite, and imogolite. Clays and Clay Minerals 30(2), 143-149.

Verwey, E.J.W. and Overbeek, J.T.G. (1948) Theory of the Stability of Lyophobic Colloids, Elsevier, Amsterdam.

Weston, D.P., Ramil, H.L. and Lydy, M.J. (2013) Pyrethroid insecticides in municipal wastewater. Environmental Toxicology and Chemistry 32(11), 2460-2468.

Yalkowsky, S.H., He, Y. and Jain, P. (2010) Handbook of Aqueous Solubility Data Second Edition, CRC Press, Taylor \& Francis Group, LLC, Boca Raton, FL.

Yoshinaga, N. and Yamaguchi, M. (1970) Adsorption of polyphosphates by allophane. Soil Science and Plant Nutrition 16(3), 121-127. 

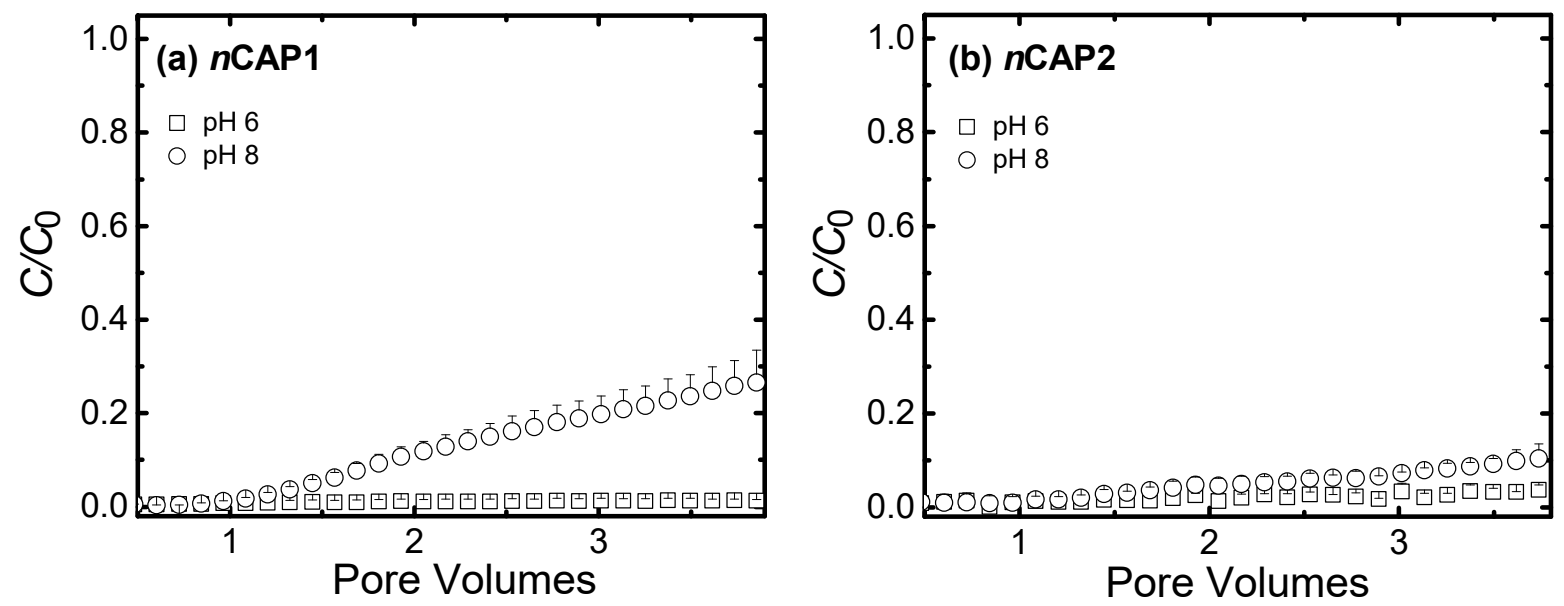

Fig. 1 - Comparison of (a) nCAP1 and (b) nCAP2 deposition behavior in loamy sand-packed columns at $\mathrm{pH} 6$ and 8 (4 PV injection time). 

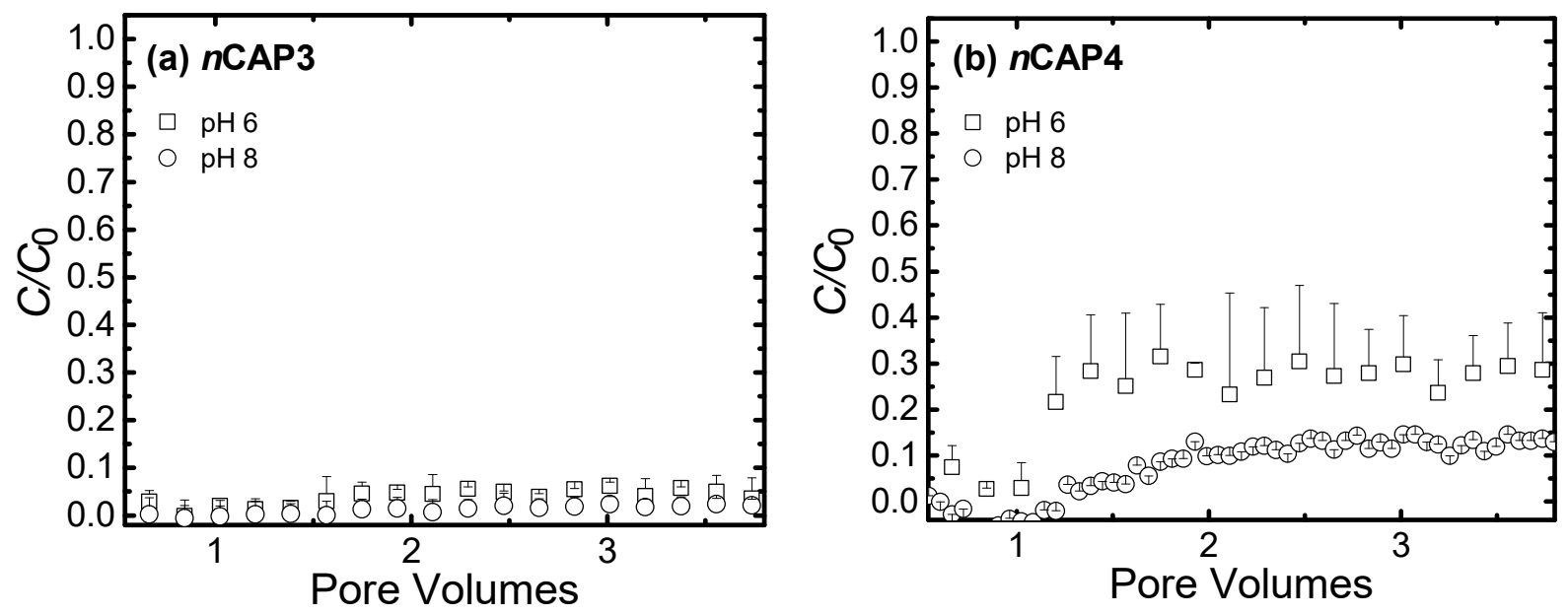

Fig. 2 - (a) nCAP3 and (b) nCAP4 deposition behavior in loamy sand-packed columns at $\mathrm{pH} 6$ and 8 (4 PV injection time). 
(a) quartz sand, $10 \mathrm{mM} \mathrm{NaNO}$

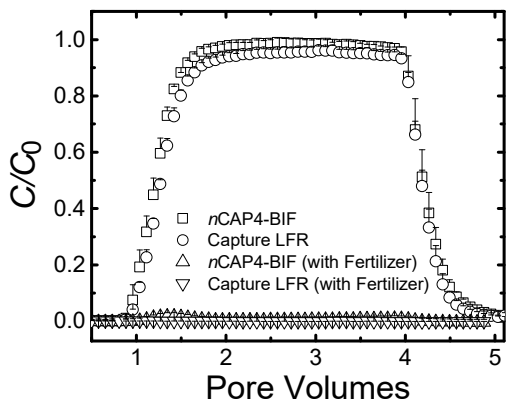

(b) quartz sand, CIPAC D

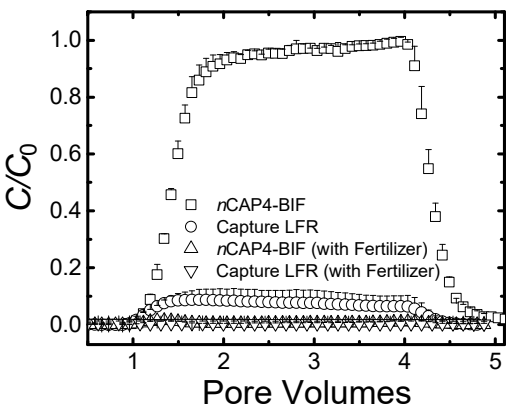

(c) loamy sand, CIPAC D

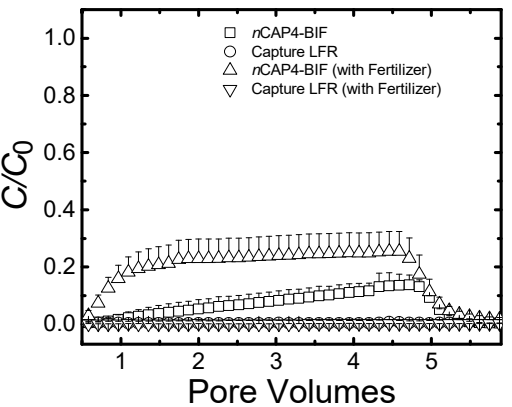

Fig. 3 - nCAP4-BIF and Capture LFR transport potential comparisons in (a) quartz sand saturated with $10 \mathrm{mM} \mathrm{NaNO}_{3}$, (b) quartz sand saturated with CIPAC D, and (c) loamy sand saturated with CIPAC D. All experiments were conducted at $\mathrm{pH} 6$. 
(a) quartz sand

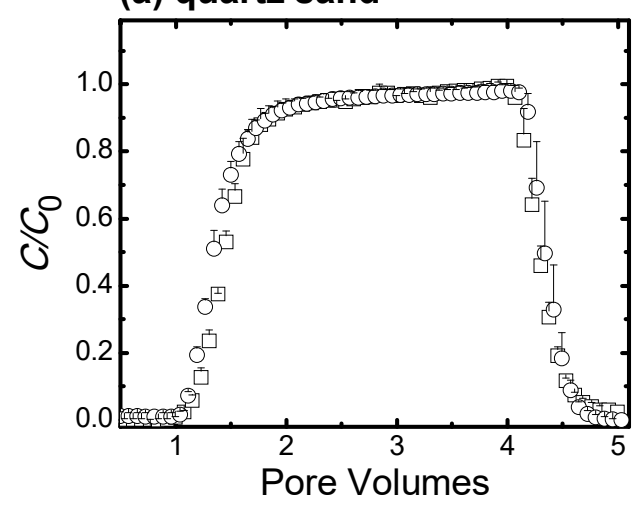

(b) loamy sand

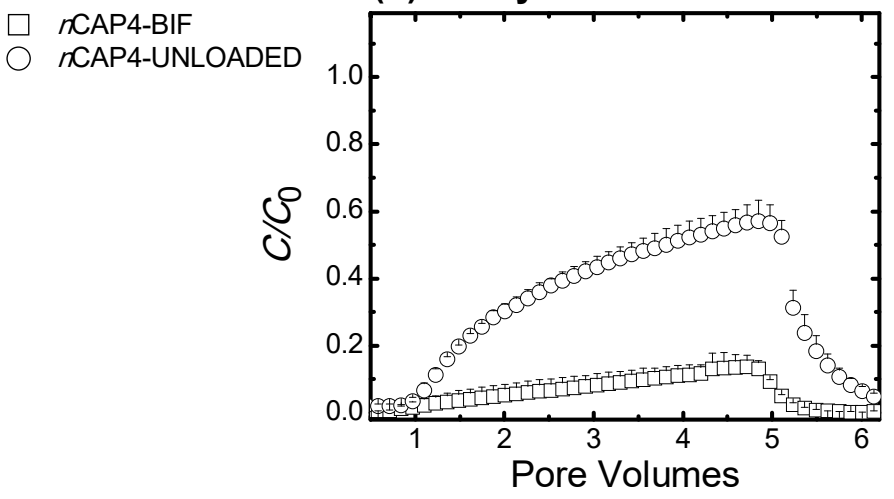

Fig. 4 - Comparing the transport potential for $n$ CAP4-BIF and $n C A P 4-U N L O A D E D$ in (a) quartz sand and (b) loamy sand packed columns saturated with CIPAC D ( $\mathrm{pH}$ 6). 
Table 1 - A summary of hollow polymeric nanocapsule (nCAP) DLS size, PdI and EPM in CIPAC D under all experimental conditions (average $\pm 95 \% \mathrm{CI}$ ).

\begin{tabular}{|c|c|c|c|c|c|}
\hline Particle Type & pH & & Size $(n m)$ & Pdl & $\operatorname{EPM}\left(\mu \mathrm{mcmV}^{-1} \mathrm{~s}^{-1}\right)$ \\
\hline \multirow{4}{*}{$n$ CAP1 } & \multirow{2}{*}{6} & Influent & $258 \pm 7$ & $0.10 \pm 0.02$ & $-0.89 \pm 0.02$ \\
\hline & & Effluent & $118 \pm 26$ & $0.49 \pm 0.08$ & $-0.60 \pm 0.17$ \\
\hline & \multirow{2}{*}{8} & Influent & $200 \pm 3$ & $0.03 \pm 0.01$ & $-1.0 \pm 0.03$ \\
\hline & & Effluent & $191 \pm 3$ & $0.03 \pm 0.02$ & $-1.0 \pm 0.05$ \\
\hline \multirow{4}{*}{$n$ CAP2 } & \multirow{2}{*}{6} & Influent & $300 \pm 35$ & $0.46 \pm 0.04$ & $-0.77 \pm 0.08$ \\
\hline & & Effluent & $176 \pm 11$ & $0.41 \pm 0.08$ & $-0.48 \pm 0.15$ \\
\hline & \multirow{2}{*}{8} & Influent & $364 \pm 9$ & $0.21 \pm 0.03$ & $-0.68 \pm 0.02$ \\
\hline & & Effluent & $197 \pm 17$ & $0.40 \pm 0.05$ & $-0.68 \pm 0.09$ \\
\hline \multirow{4}{*}{$n$ CAP3 } & \multirow{2}{*}{6} & Influent & NA & NA & $-0.97 \pm 0.03$ \\
\hline & & Effluent & $91 \pm 19$ & $0.66 \pm 0.14$ & $-0.33 \pm 0.18$ \\
\hline & \multirow{2}{*}{8} & Influent & $168 \pm 19$ & 1 & $-0.68 \pm 0.05$ \\
\hline & & Effluent & $283 \pm 45$ & $0.57 \pm 0.05$ & $-0.26 \pm 0.02$ \\
\hline \multirow{4}{*}{$n$ CAP4 } & \multirow{2}{*}{6} & Influent & $169 \pm 19$ & 1 & $-0.61 \pm 0.05$ \\
\hline & & Effluent & $244 \pm 58$ & $0.67 \pm 0.04$ & $-0.21 \pm 0.03$ \\
\hline & \multirow{2}{*}{8} & Influent & $168 \pm 52$ & $0.98 \pm 0.05$ & $-0.48 \pm 0.04$ \\
\hline & & Effluent & $234 \pm 44$ & $0.90 \pm 0.06$ & $-0.29 \pm 0.03$ \\
\hline
\end{tabular}


Table 2: A summary of $n$ CAP4-BIF and Capture ${ }^{\circledR}$ LFR DLS size, PdI and EPM under all experimental conditions (average $\pm 95 \% \mathrm{CI}$ ).

\begin{tabular}{|c|c|c|c|}
\hline \multicolumn{4}{|c|}{$n$ CAP4-BIF } \\
\hline Electrolyte (pH 6) & Size (nm) & Pdl & EPM $\left(\mu \mathrm{mcmV}^{-1} \mathrm{~s}^{-1}\right)$ \\
\hline $10 \mathrm{mM} \mathrm{NaNO}_{3}$ & $288 \pm 7$ & $0.34 \pm 0.03$ & $-6.02 \pm 0.26$ \\
\hline $10 \mathrm{mM}$ CIPAC D & $332 \pm 15$ & $0.31 \pm 0.06$ & $-2.19 \pm 0.05$ \\
\hline $10 \mathrm{mM} \mathrm{NaNO}_{3}+$ Fertilizer & $432 \pm 2$ & $0.09 \pm 0.04$ & $-2.23 \pm 0.10$ \\
\hline 10 mM CIPAC D + Fertilizer & $519 \pm 16$ & $0.19 \pm 0.03$ & $-2.36 \pm 0.10$ \\
\hline \multicolumn{4}{|c|}{ Capture LFR } \\
\hline Electrolyte (pH 6) & Size (nm) & Pdl & $\mathrm{EPM}\left(\mu \mathrm{mcmV} \mathrm{v}^{-1} \mathrm{~s}^{-1}\right)$ \\
\hline $10 \mathrm{mM} \mathrm{NaNO}_{3}$ & $393 \pm 11$ & $0.25 \pm 0.05$ & $-4.86 \pm 0.17$ \\
\hline 10 mM CIPAC D & $710 \pm 67$ & $0.39 \pm 0.03$ & $-1.53 \pm 0.06$ \\
\hline $10 \mathrm{mM} \mathrm{NaNO}_{3}+$ Fertilizer & $1886 \pm 246$ & $0.16 \pm 0.03$ & $-0.87 \pm 0.06$ \\
\hline 10 mM CIPAC D + Fertilizer & $1880 \pm 109$ & $0.19 \pm 0.08$ & $-1.01 \pm 0.11$ \\
\hline
\end{tabular}

